\section{Reply to Comstock}

\section{Kathryn P. George}

Gary Comstock deserves praise for his courage in reexamining his own beliefs about our duties toward animals. Awakening from one's dogmatic slumbers can be a painful process indeed. While the thrust of my criticisms concerns the incompleteness of his discussion, I urge him to continue his thinking on the subject. The issues of the nature and extent of our moral obligations to animals are far from settled. It seems to me that people with a farming background may have within them an understanding of the nature of the ethical relationship among humans and other species which might provide valuable insight if brought to light. Also, lest readers think my defense of including Regan's ideas in any discussion of these issues constitutes agreement with his method and conclusions, I refer them to my own naturalistic approach to our dealings with animals ${ }^{1}$

In addition, I seem to have struck a chord with Comstock on the issue of theological approaches to these questions. A rereading of my comments should make it clear that I do not argue that theological approaches should be "excluded from the conversation." Rather, I question the universality of such approaches. It seems to me that more than just Christian views ought to be included. Comstock justifies not including secular ethical theories on the grounds that these discussions are available elsewhere. The same might be said of theological approaches. My overall concern is with the balance and completeness of the discussion of ethical foundations in this volume. Here's why: the likely readership for the volume is not going to be comprised of philosophers and theologians. The great majority will be scientists and students from the agricultural disciplines. These individuals may tend to take the view that Comstock is an ethical expert and may accept his

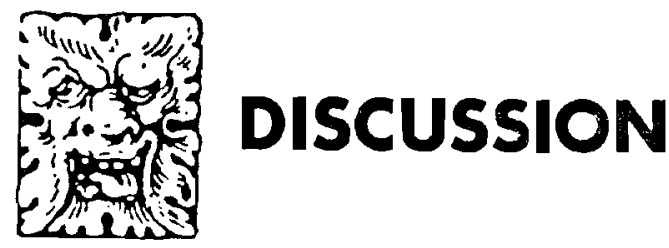

comments as authoritative. Many scientists do not know that ethical theories of any kind exist and often think either that ethics must come from obedience to divine command or else that one's ethical ideas are totally a matter of subjective opinion. ${ }^{2}$

Secular ethical theories, in contrast to theological approaches, try to include all of our most cherished ethical principles (whether found as a part of religion or not) within a consistent and coherent framework. These theories aim to be "ethically ecumenical" in that they appeal to or are founded upon a common human understanding that includes feelings, emotion, and reason. Ethical theories aim to satisfy the fundamental demand for universality-that we would ourselves agree to the choices and justifications made by another in similar circumstances.

Moreover, a person who lives by a set of such secularized ethical principles need not be irreligious. She may simply see that a Christian conscience demands that one's principles be consistent, coherent, and open to the understanding even of those who do not worship or worship in other ways. It seems to me that the duty of a Christian and that of an atheist are the same with respect to being ethical. Using both heart and mind, each must try to live in accordance with principles and virtues which others can understand and assent to. The Christian has the added task of understanding for himself a coherent (and not too heretical) image of a deity with attributes worthy of worship. A Christian might hope for divine guidance or a form of grace to assist him in his ethical quest, but he can never simply assume he will receive it, as this would alter the nature of the inquiry.

As for public God-talk, unfortunately this often leads people away from the issues of making our own principles and virtues consistent and coherent to demanding that others accept the authority of one's religious beliefs. The conversation comes to consist of absolutist appeals to the God's authority, buttressed by citations from Scripture which more often than not are interpreted in such a way as to permit the conclusions one has already accepted as true. Opponents who remain unconvinced about the metaphysical religious beliefs are then sometimes labelled immoral regardless of their conduct.

This is not to say that secular rational methods are squeaky clean and flawless. They are not. But ideally, a secular ethicist wants to include at least for initial consideration the basic moral tenets of all creeds and 
ways of life, to test them by rational criteria and hypothetical real life examples which take account of social, psychological, and scientific facts, too.

As a secular ethicist, I see no objection to including Christian principles for test. I simply won't limit the talk to only these. Given what appears in his anthology, Comstock's charge that I would cut short the conversation might as a shoe fit better on his own foot.

Notwithstanding the shortcomings in ethical discussion, Comstock has given us an excellent anthology, the only one of its kind to include discussions from so many disciplines on the important issue of the loss of our family farms. As such, it does much to "continue the conversation."

\section{Notes}

${ }^{1}$ Kathryn P. George, "So Animal a Human... Or the Moral Relevance of Being an Omnivore," Journal of Agricultural Ethics 3:2 (1990): 172-186.

2 This information comes from my own personal dealings with scientists, agriculturalists, and ordinary people in workshop settings and in reviewing interdisciplinary articles for publication. For a similar observation, see Bernard Rollin's discussion of the general belief among scientists that ethics is not open to rational inquiry, in his The Unheeded Cry: Animal Consciousness, Animal Pain, and Science (Oxford University Press, 1989).

\section{If You Really Care About} Animals, You Need to Read The ANIMALS' AGENDA

From factory farming to Native trapping, from endangered species to companion animals, we cover the issues that are making animal rights a major movement of the 20th century.

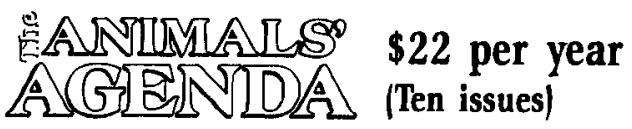

P.0. Box 6809 • Syracuse, NY 13217

\section{cosarida}

Cosmetic: Purporting to improve beauty, correcting defects, supplying deficiencies; involving or producing an apparent or superficial concession, improvement, etc., without any real substance to it.

- Chambers 20th Century Dictionary

How many rabbits blinded for me? An eye for an eye, no more

eyes to find food, escape

white-coated predators

slower at kill than fox, than owl longer the pain

by days by years.

No tears

from red eyes

no living rain

washes out

red pools of pain.

For my eyes sapphire blue, jade green, plum frost, aquamarine no red.

Red eyes mean tears.

Their eyes are not made for tears.

I must not cry my eyes will run I can not see what must be done. 